\title{
Leveraging Public Healthcare Dollars to Fund Critical Time Intervention: A Proposal for a Scalable Solution to Crisis Homelessness in the United States
}

\author{
Thomas Byrne, Ph.D 1 | Dennis P. Culhane, Ph.D 1
}

1 Boston University School of Social Work 2 University of Pennsylvania School of Social Policy and Practice

Corresponding Author: Thomas Byrne Email: tbyrne@bu.edu

All content published in IJOH is licensed under a Creative Commons AttributionNonCommercial-ShareAlike 4.0

International license (CC BY-NC-SA 4.0).

Received: 28 Feb 2021

Accepted: 7 Jan 2022

\begin{abstract}
Recent experience demonstrates that substantial progress in reducing homelessness is possible if resources are directed towards evidence-based, housing-focused solutions. However, the homeless assistance systems in most countries are not adequately resourced to assist persons experiencing "crisis homelessness," who account for the majority of the homeless population. Thus, we present a policy proposal for leveraging an expansion of Critical Time Intervention (CTI), an evidence-based behavioral health intervention, as a scalable solution for crisis homelessness. We draw on the specific policy context of the United States in proposing the use of funds from Medicaid, the public health insurance program for low-income individuals, to finance such an expansion, but argue our broader policy proposal has salience internationally as well. In presenting our proposal, we discuss why it represents a sound and feasible policy idea, focusing on the alignment between CTI and a promising new programmatic approach known as rapid rehousing. We describe the potential benefits of enacting this proposal and conclude with discussing the United States-specific and more general challenges that would need to be addressed to implement it, including the need for additional resources to cover the costs of the temporary financial assistance component of rapid re-housing.
\end{abstract}

Keywords

Homelessness, Critical Time Intervention, Rapid Re-Housing, Policy, United States

\section{Introduction}

In the United States (U.S), roughly 1.45 million persons will stay in a homeless shelter or transitional housing program at some point over the course of a year (U.S. Department of Housing and Urban Development, 2020a). Research documents a clear link between homelessness and an array of adverse health outcomes (Hwang, 2001). Homelessness is also costly to society, with studies showing that persons experiencing homelessness utilize a constellation of emergency shelter, acute health, behavioral health, criminal justice, and other services that 
can cost tens of thousands of dollars annually (Latimer et al., 2017; Ly \& Latimer, 2015). In the United States, the health care delivery system, and public health care payers in particular, often bear the brunt of these costs.

Thus, while homelessness is a serious social, economic, and health problem, it is not intractable. Recent experience from several countries demonstrates that substantial progress in reducing homelessness is possible if resources are directed towards evidence-based, housingfocused solutions. Indeed, in the United States, the expansion of permanent supportive housing (PSH) - an evidenced-based intervention defined broadly as subsidized housing matched with ongoing supportive services-has been linked with aggregate reductions in the number of individuals experiencing chronic homelessness (Byrne et al., 2014) and the number of homeless military veterans (Evans et al., 2019). Significant reductions in homelessness in Finland have also been attributed to PSH (Y Foundation, 2018), and research from Canada shows that individuals with serious mental illness who are provided access to PSH are able to maintain high rates of housing stability for at least six years (Stergiopoulos et al., 2019).

However, PSH is intended primarily for high-need individuals experiencing chronic homelessness, who comprise a small minority of all single homeless adults in the United States and elsewhere (U.S. Department of Housing and Urban Development, 2017). With annual costs that can exceed $\$ 15,000$, it may not be feasible or Figure 1

Percent Change in Point-in-Time Counts of Persons Experiencing Crisis and Chronic Homelessness in the United States, 2007-2019

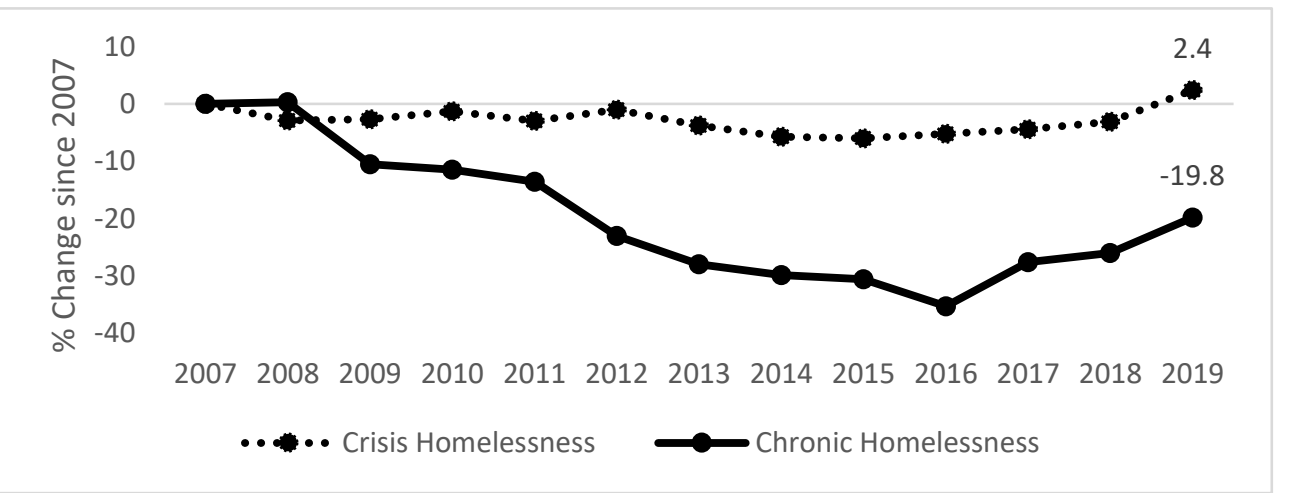

Source: Author Calculations based on 2019 Annual Homeless Assessment Report to Congress, Part 1.

Notes: Number of persons experiencing crisis homelessness estimated by subtracting the total number of persons experiencing chronic homelessness in each year from the total number of persons experiencing homelessness as an individual. 2007 is the base year.

211 | International Journal on Homelessness: https:/ /ijoh.ca necessary to provide such an intensive intervention to all persons experiencing homelessness.

There is thus a need for alternative solutions that are less resource-intensive but equally effective as PSH for the bulk of the homeless population, which is comprised of individuals who are not chronically homelessness. These persons might best be described as experiencing "crisis" homelessness, in that their homeless experience is brief and is often preceded by a triggering event such as an eviction, dissolution of a relationship, or transition out of an institutional living arrangement such as foster care, prison, or substance abuse treatment. The U.S. Department of Housing and Urban Development (HUD) does not separately report estimates of the number of persons experiencing crisis homelessness. However, we used existing HUD data on the size of the sheltered homeless population to estimate the number of people experiencing crisis homelessness. By our estimates, in the United States, about 1.17 million persons, or roughly $82 \%$ of the overall sheltered homeless population experience crisis homelessness each year, of whom about 887,000 (or nearly two-thirds of the overall shelter-using homeless population) are single adults (U.S. Department of Housing and Urban Development, 2017). As illustrated in Figure 1, progress in addressing crisis homelessness over the last decade plus has lagged far behind that achieved for chronic homelessness. 
The onset of the Covid-19 pandemic cast the need to address crisis homelessness in a new and more urgent light. On the one hand, the macroeconomic shock wrought by the pandemic raised concerns about large increases in homelessness in the United States and other countries. On the other hand, congregate shelter-the default emergency housing intervention in many countries - was ill-suited for the social distancing, isolation, and quarantining measures necessary to reduce exposure and prevent transmission of the novel coronavirus (Culhane et al., 2020; Perri et al., 2020). In many countries, national and local governments responded accordingly, quickly injecting significant monetary resources and policy measures to prevent homelessness and making aggressive use of hotels to house individuals experiencing homelessness (Parsell et al., 2020).

The swift response to homelessness in response to the Covid-19 pandemic comes on the heels of the emergence of a new paradigm in the homelessness assistance sector in the United States, Canada, several European countries, and Australia that emphasizes prevention-oriented approaches to homelessness (Dej et al., 2020). Taken together, these developments provide a unique opening for making progress in reducing crisis homelessness. This paper presents the case for leveraging Critical Time Intervention (CTI), an evidence-based behavioral health intervention (Herman et al., 2007), as a scalable policy solution for crisis homelessness in the United States. To provide context for this proposal, we first describe the ongoing paradigm shift in the homeless assistance system that has spurred interest in a relatively new programmatic approach known as "rapid rehousing" (RRH). We then explain why pairing CTI and RRH makes for sound and feasible policy, highlighting the potential benefits of our proposal to individuals and society. We conclude by discussing the challenges that need to be addressed to make this proposal a reality.

In presenting our case for a CTI-based $\mathrm{RRH}^{1}$ intervention as a scalable solution to crisis homelessness, we focus on the United States, as that is the policy context with which we are most familiar. A key part of the proposal focuses on how funding from Medicaid, which is the United States' public health insurance program for people with low-income, might be used to finance our proposal, as this is arguably the most salient issue regarding our proposal in the American context. However, while we offer a perspective from the United States, we believe that a CTI-based RRH intervention is likely to be a viable solution to addressing crisis homelessness in other countries as well. In particular, we believe that the conceptual case and likely benefits from scaling up a CTI-based $\mathrm{RRH}$ approach that we outline, as well as the potential implementation challenges associated with our proposal, would likely be broadly similar in many countries. Thus, throughout our discussion, we attempt to make a distinction between what we believe are issues that are salient specifically for the United States and those that are likely to be relevant in other countries as well.

\section{Housing Stabilization as the Emerging Paradigm for Homelessness Assistance Systems}

For much of the past 25 years and beyond, emergency shelters and soup kitchens have represented the primary and often only available forms of assistance for persons experiencing homelessness in the United States and in many other countries in the global North (Dej et al., 2020). While serving important survival functions, these programs offer little in the way of practical assistance for resolving a housing crisis. In more recent years prior to the onset of the Covid-19 pandemic, the United States witnessed the emergence of a conceptual framework that fits a conceptual understanding of homelessness as an acute housing crisis and aligns with the observed dynamics of homelessness as a phenomenon that is, for the majority of persons, brief and non-recurrent in nature (Culhane et al., 2011). As Figure 2 shows, housing stabilization has replaced emergency shelter as the core concept in this framework in

\footnotetext{
${ }^{1}$ In this paper, we use the terms "CTI-based RRH," "CTI$\mathrm{RRH}$ " and "CTI/RRH" interchangeably to refer to an intervention that integrates both CTI and RRH.
} 
reflection of a new, narrowly focused mission for the homelessness assistance system on triage and stabilization. While this figure best reflects the conceptual orientation that has taken root in the United States, other countries have also shifted their approach to homelessness towards strategies that embrace prevention and housing stabilization, and Dej and colleagues (2020) offer a helpful conceptual model for preventionoriented approaches to homelessness.

\section{Figure 2}

Housing Stabilization as the Emerging Paradigm for Homeless Assistance Systems

Prevailing Model

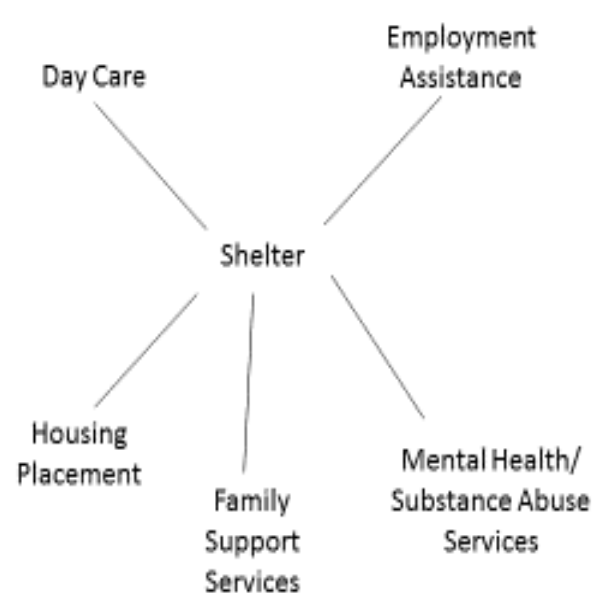

The emergence of new paradigms that embrace homelessness prevention and housing stabilization has coincided with the introduction of programmatic approaches that have applied its concepts. In the United States, the onset of the economic recession in 2008 catalyzed this process, as the American Recovery and Reinvestment Act of 2009 included $\$ 1.2$ billion for the Homelessness Prevention and RRH Program (HPRP). Instead of paying for brick and mortar residential programs, HPRP provided funds to states and localities to be used flexibly for shortterm housing costs and case management services geared towards preventing homelessness among those at-risk, and rapidly re-housing those experiencing homelessness. Although HPRP expired after three years, evidence points to its effectiveness in reducing aggregate rates of homelessness (Piña \& Pirog,

\section{Emerging Model}

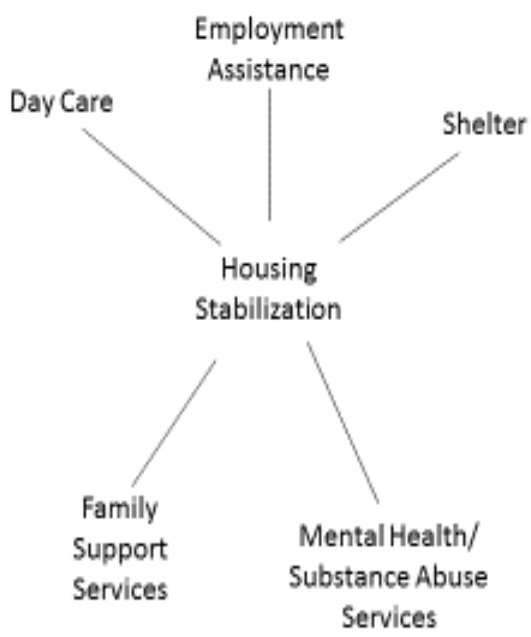

2019), and the reauthorization of federal homeless assistance programs in 2009 (the HEARTH Act) made an increased emphasis on RRH permanent. In 2011, the U.S. Department of Veterans Affairs launched its own homelessness prevention and RRH initiative, the Supportive Services for Veteran Families (SSVF) program, which represented the first planned, national program to adopt housing stabilization as its core purpose.

$\mathrm{RRH}$ is most prevalent in the United States, but the use of the approach is growing internationally. RRH is part of the European Observatory on Homelessness' typology of homelessness services in Europe, and RRH is being used in several European countries, including France, Ireland, and the United Kingdom (Pleace et al., 2018). Moreover, in response to the Covid-19 pandemic, the United 
States and other countries have increased funding for RRH. For example, the Scottish government updated its homelessness strategy in response to the pandemic with a proposal to expand RRH to replace the use of congregate shelters (Scottish Government, 2020).

Evidence on the impact of RRH for single adults is highly limited, but there is some evidence of its impact of reducing returns to emergency shelter in this population (Rodriguez \& Eidelman, 2017). Moreover, more rigorous research of the impact of $\mathrm{RRH}$ for families suggests that RRH is no worse in promoting housing stability than emergency shelter or transitional housing and is less costly than either (Gubits et al., 2018). However, the availability of RRH for non-veteran single adults in the United States remains highly limited. In 2019, there were only 30,229 RRH slots available for single homeless adults. By comparison, there were more than eight times as many PSH beds $(243,528)$, nearly five times as many emergency shelter beds $(147,350)$, and more than one and a half times as many transitional housing beds $(49,660)$ for this population (U.S. Department of Housing and Urban Development, 2020b).

\section{Adapting Critical Time Intervention to Expand Rapid Re-Housing}

Taking a CTI-based RRH intervention to scale would make for a sound and feasible policy Table 1 response to crisis homelessness for three reasons. First, there is close alignment between the CTI and RRH conceptual and program models, thus facilitating the implementation of an integrated CTI-RRH model. Second, CTI has a strong evidence base as an effective intervention for reducing homelessness. Third, in the United States, federal guidance suggests that most of the services at the core of a CTI-based RRH program could be reimbursed by Medicaid, thereby providing the necessary funding to scale up the approach. We expand on each of these points below.

\section{Alignment of Critical Time Intervention and Rapid Re-Housing}

RRH and CTI share nearly identical conceptual foundations and program models, as illustrated in Table 1. Originally developed for persons with serious mental illness leaving emergency shelter, CTI seeks to foster community-based supports for highly vulnerable individuals during periods of transition with the ultimate aim of helping them to obtain stability in the community (Herman et al., 2007). From the outset, the intervention was intended to apply to persons exiting a range of institutional settings, including those exiting psychiatric hospitals, incarceration, and homelessness (Herman et al., 2007).

Alignment of Critical Time Intervention, Rapid Re-housing and Federal Guidance on Medicaid Coverage of Housing Related Activities E Services

\begin{tabular}{|c|c|c|c|}
\hline & Critical Time Intervention & Rapid Re-housing & $\begin{array}{l}\text { United States Federal } \\
\text { Guidance from the Centers } \\
\text { for Medicare and Medicaid } \\
\text { Services }\end{array}$ \\
\hline $\begin{array}{l}\text { Program } \\
\text { Structure }\end{array}$ & $\begin{array}{l}\text { - Time-limited, flexible } \\
\text { intervention focused on } \\
\text { assisting persons forge } \\
\text { connections to supports } \\
\text { during the period of } \\
\text { transition. } \\
\text { - Three phases of } \\
\text { decreasing intensity: } \\
\text { Transition phase: } \\
\text { Establish connections }\end{array}$ & $\begin{array}{l}\text { - Time-limited, } \\
\text { flexible intervention } \\
\text { focused on helping } \\
\text { households exit } \\
\text { homeless and } \\
\text { stabilize in housing } \\
\text { - Activities organized } \\
\text { into three categories: } \\
\text { Obtain \& move } \\
\text { into housing }\end{array}$ & $\begin{array}{l}\text { - Clarifies circumstances } \\
\text { under which Medicaid } \\
\text { funds can be used for } \\
\text { housing-related services } \\
\text { - Intended to help states } \\
\text { design benefit programs } \\
\text { that include housing- } \\
\text { related activities and } \\
\text { services }\end{array}$ \\
\hline
\end{tabular}

214 | International Journal on Homelessness: https:/ /ijoh.ca 


\begin{tabular}{|c|c|c|c|}
\hline & $\begin{array}{l}\text { to community-based } \\
\text { supports } \\
\text { Try-out phase: Monitor } \\
\text { strength of a network } \\
\text { of supports and adjust } \\
\text { as necessary } \\
\text { Transfer of care: } \\
\text { Complete transfer of } \\
\text { care to community base } \\
\text { supports \& end } \\
\text { services }\end{array}$ & $\begin{array}{l}\text { Support } \\
\text { stabilization in } \\
\text { housing through } \\
\text { connections to } \\
\text { community-based } \\
\text { supports } \\
\text { Close the case } \\
\text { once the risk of } \\
\text { homelessness is no } \\
\text { longer imminent }\end{array}$ & \\
\hline $\begin{array}{l}\text { Key } \\
\text { Activities/S } \\
\text { ervices }\end{array}$ & $\begin{array}{l}\text { - } \text { Case management } \\
\text { provides flexible forms of } \\
\text { assistance, including: } \\
\text { Develop \& } \\
\text { implement a plan to } \\
\text { link clients to } \\
\text { family/friends, } \\
\text { service providers, and } \\
\text { other supports } \\
\text { Mediate conflicts } \\
\text { between client \& } \\
\text { family/other supports } \\
\text { Give support and } \\
\text { advice to clients and } \\
\text { supports }\end{array}$ & 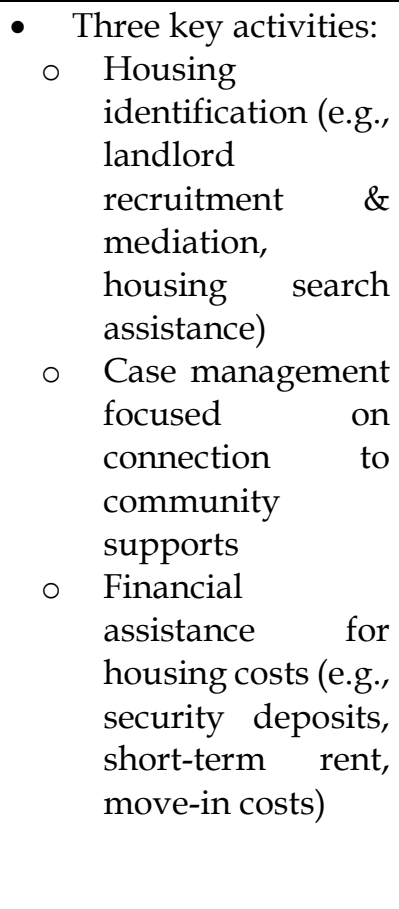 & $\begin{array}{l}\text { - Two types of individual- } \\
\text { level housing-related } \\
\text { activities \& services: } \\
\text { Housing transition } \\
\text { services that support an } \\
\text { individual's ability to } \\
\text { prepare for and } \\
\text { transition into housing } \\
\text { (e.g., develop } \\
\text { individual housing } \\
\text { support plan, housing } \\
\text { search, assistance, } \\
\text { assist with move-in) } \\
\text { Housing \& tenancy } \\
\text { sustaining services } \\
\text { (e.g., tenant education, } \\
\text { mediating disputes } \\
\text { with } \\
\text { landlords/neighbors, } \\
\text { linkage } \\
\text { community resources) }\end{array}$ \\
\hline $\begin{array}{l}\text { Target } \\
\text { Population }\end{array}$ & $\begin{array}{l}\text { Persons in periods of } \\
\text { transition, including } \\
\text { those exiting: } \\
\text { Emergency Shelter } \\
\circ \text { Psychiatric } \\
\text { hospitalization } \\
\circ \text { Incarceration }\end{array}$ & $\begin{array}{l}\text { - Those experiencing } \\
\text { "crisis } \\
\text { homelessness" } \\
\text { including those } \\
\text { whose homeless is } \\
\text { trigged by: } \\
\text { ○ Discharge from } \\
\text { prison/jail } \\
\text { Discharge from } \\
\text { detox } \\
\text { /psychiatric } \\
\text { hospitalization } \\
\text { Eviction } \\
\text { Exit from foster } \\
\text { care } \\
\text { Dissolution of } \\
\text { relationship }\end{array}$ & 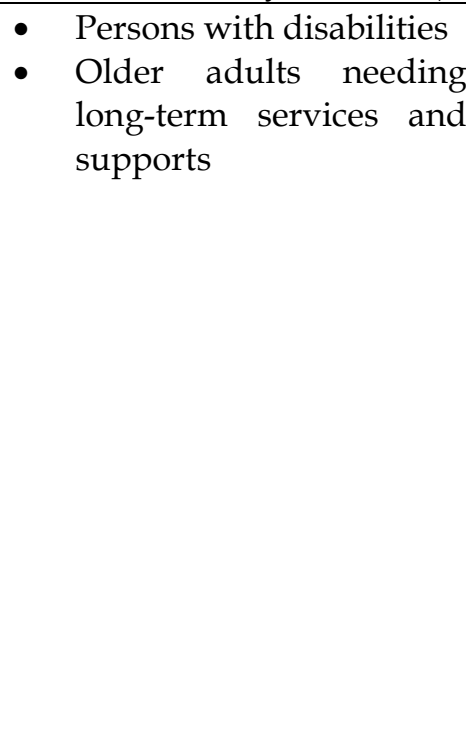 \\
\hline
\end{tabular}


In its original design, CTI comprises of three phases, lasting three months each and involving decreasingly intensive services. The first phase is the "transition" phase, which commences prior to a participant's discharge from a shelter or other institutional setting. This phase focuses on implementing a transition plan to connect participants to the people and service agencies that will provide them with the necessary support for community living. During the second "try-out" phase, CTI caseworkers monitor how well the community-based forms of support are working for the client and to make adjustments as needed. In the third "transfer of care" phase, the transfer of care from the caseworker to the community-based forms of support is completed.

For its part, RRH emphasizes helping households quickly exit homelessness and stabilize in housing in the community. The three core components of RRH are: 1) Housing identification, with the goal of helping participants find housing as quickly as possible; 2) Temporary financial assistance for move-in costs, security deposits, or short-term rental assistance; and 3) Case management services, with the goal of helping households stabilize in housing (National Alliance to End Homelessness, 2016). RRH is highly flexible and tailored to individual needs, and like CTI, RRH is also a time-limited intervention that generally lasts from three to nine months. In concept, RRH also follows a staged approach with the first stage focused on helping participants return to former housing or obtain new housing. The second stage is geared towards helping participants access necessary supports in the community, including family, friends, and mainstream health and social services; and the third stage ends services when a participant is stably housed and no longer facing a serious risk of homelessness.

The alignment of the RRH and CTI approaches means that CTI could be easily adapted to fit into RRH programs serving persons experiencing crisis homelessness. In fact, some RRH programs in the United States have already integrated CTI into their program models (Connecticut Coalition to End Homelessness, 2018), as we describe in more detail below. Thus, prior work provides both proof of concept and a knowledge base that could be harnessed in a larger-scale expansion of a CTI-based RRH model.

\section{Critical Time Intervention is an Evidence- Based, Cost-Effective Intervention}

CTI is an evidence-based intervention, with several randomized controlled trials demonstrating its effectiveness in reducing homelessness among persons with serious mental illness (Herman et al., 2011; Susser et al., 1997). When coupled with the temporary financial assistance that is an essential component of RRH, CTI could multiply the impact of RRH programs on a dollar-for-dollar basis. Studies have also linked CTI with reductions in inpatient hospitalizations, outpatient mental health services, emergency department use, substance abuse treatment and public assistance (Herman et al., 2007).

\section{Using Medicaid to Fund Critical Time Intervention in an RRH Context}

As the public health insurance program for low-income Americans, Medicaid is an entitlement program that operates as a joint program between the federal government and the individual states. States administer their own Medicaid programs in accordance with broad federal guidelines, and funding for Medicaid is split between the federal government and states. Overall, roughly 97 million people-or nearly $30 \%$ of all Americans-are Medicaid beneficiaries (Priorities, 2020).

Federal guidance suggests that Medicaid dollars could be used to finance an expansion of an adapted version of CTI as a RRH intervention. In 2015, the federal government issued guidelines on two allowable uses of Medicaid funds for housing-related activities (Center for Medicare \& Medicaid Services, 2015). The first are services that support an individual's ability to transition into housing, including the development of an individualized housing support plan, assistance with the housing search process, and assistance in supporting other details of the move. The second type of services were those focused on helping individuals sustain tenancy after moving into housing, such as tenant education, assistance in resolving landlord-tenant disputes, and linkages with community resources to foster integration and well-being. 
As illustrated in Table 1, CTI and its key services fit within the scope of Medicaid reimbursable activities under these federal guidelines. While the guidelines state that such services are only reimbursable for older adults or those with disabilities, they do not appear to require an individual to have a long-term disability. Therefore, these guidelines could apply to a broader group of people, including those who are temporarily disabled by an acute substance abuse disorder and who are exiting residential substance abuse treatment or incarceration. Similarly, the guidelines could apply to those who may have less permanent or severe mental illnesses, such as post-traumatic stress disorder, stemming from domestic violence or untreated trauma exposures as children. This point is crucial, as the majority of persons experiencing crisis homelessness in the United States likely do not have a permanent disability but may meet a broader definition of disability. Moreover, CTI-based rapid rehousing could be argued as a medical necessity for such people because homelessness would otherwise threaten their ability to recover from these disabilities or succeed in treatment.

One of the key results of the Affordable Care Act, the health care reform passed in 2010 under President Barack Obama, is that states were able to expand their Medicaid programs to cover lowincome single adults, who in most states had not previously been eligible for Medicaid coverage. As of 2021, 39 states have expanded Medicaid to cover this population. In these states, single adults experiencing crisis homelessness constitute one of the largest groups of those newly-eligible for Medicaid and a primary target population of the expansion (DiPietro et al., 2014). Thus, Medicaid offers a new pool of previously unavailable federal entitlement resources to assist this population in regaining stable housing in the community and successfully recovering from mental illness and/or substance use disorders.

\section{Opportunity and Impact}

Implementing our proposal would have benefits at multiple levels. First, at the individual level, the housing stability and connections to community-based treatment and supports afforded by CTI would lead to improved health, social and economic outcomes for those receiving assistance. Research demonstrates that access to stable housing for persons experiencing homelessness is associated with a lower risk of mortality (Schwarcz et al., 2009) and that housing stability provides a platform for developing stronger social ties (Henwood et al., 2015). Moreover, prior studies have documented a link between CTI and reduced utilization of public assistance (Jones et al., 2003), thus highlighting the collateral economic benefits and improved prospects for self-sufficiency among those receiving assistance. Second, the implementation of our proposal would have a number of benefits to society, the most notable being a substantial reduction in overall homelessness. Society would also benefit from the reduced utilization of emergency shelter, health services, criminal justice system resources, public assistance, and other public services that have been linked with CTI (Jones et al., 2003). Finally, the Covid-19 pandemic has led to the increased use of individual hotel rooms as alternatives to congregate emergency shelter in many countries. Such settings arguably provide a better platform for accessing more permanent housing than congregate shelter, and it is likely that this practice, or something similar to it, will continue and perhaps gain prominence even when the pandemic is over. To the extent that this is the case, a CTI-based RRH model could prove crucial for helping ensure that individuals are able to benefit from the relative stability afforded by a private hotel room to transition into more permanent, stable housing.

\section{Implementation Challenges}

From a practical standpoint, scaling up integrated CTI-RRH programs would require addressing several challenges. These challenges include the need to appropriately tailor CTI for those experiencing crisis homelessness; having a trained workforce in place to deliver CTI-based $\mathrm{RRH}$, and identifying those in need of more intensive supports. These sets of challenges will be relevant in the United States as well as in countries with different policy contexts. We outline these challenges below and also discuss two additional United States-specific challenges as well: determining the best mechanism for states to include CTI in their Medicaid benefit 
package; and resolving how to pay for the temporary financial assistance component of RRH.

\section{Tailoring CTI}

CTI is flexible by design, and while it has been adapted for different populations, some fine-tuning of the model to tailor it to the needs of those experiencing crisis homelessness is required. Recent developments in the United States are promising in this regard. The Center for Advancement of Critical Time Intervention (CACTI), which has the explicit mission of supporting the broad dissemination of CTI, recently partnered with the National Alliance to End Homelessness on a pilot project to develop and test an adapted version of CTI for RRH in the U.S. state of Connecticut (Connecticut Coalition to End Homelessness, 2018). This pilot resulted in the creation of a formalized program model of CTI for RRH, which has an explicit focus on housing stabilization (Herman et al., 2017). In comparison to the original nine-month CTI model, the CTI for RRH model lasts for six months, although it envisions that the temporary financial assistance component of RRH could last for a shorter (or longer) duration. Importantly, the pilot project developed training and implementation materials, including a manual outlining staffing structure, caseload sizes, and program practices. These materials could be leveraged to disseminate the CTI for RRH model more widely.

Fine-tuning of the model is required not just to tailor it to the needs of persons experiencing crisis homelessness, but to specific sub-groups of the crisis homeless population as well. For example, individuals exiting incarceration and young adults aging out of the foster care system are both groups that face an elevated risk of homelessness and would be ideal candidates for a CTI-based RRH intervention during these transition periods. However, the specific needs of these two groups are likely to vary, and CTIbased RRH interventions would likewise need to be tailored accordingly. Thus, a key challenge for implementing CTI-based RRH interventions more broadly is to ensure that such tailoring of interventions is done rigorously as possible. In practice, this would require sufficient funding for research that can help inform the optimization of intervention delivery for different sub-groups, as well as formalized mechanisms for providers to share best practices about how to tailor CTIbased RRH for different sub-groups

\section{Training and Workforce Issues}

A large expansion of a CTI-based RRH intervention would require training a large enough workforce capable of providing the intervention with adequate quality and fidelity. The training infrastructure available through CACTI could be harnessed and expanded to support this effort. Additionally, CTI training could be integrated as a core component of professional social work training and education. Some countries might have a leg up in this area. For example, in Finland, Germany, and other European countries, "housing social work" is a distinct field of practice (Pleace et al., 2015) that focuses on securing housing, facilitating access to community resources, and promoting integration for populations with complex needs. This field of practice does not currently exist in the United States, but adopting this framework could help expand the availability of a workforce equipped to provide CTI-based RRH in the United States and in other countries.

\section{Identifying Those in Need of More Intensive Supports}

As we conceptualize it, a CTI-based RRH model would be a time-limited intervention with a scaling down of both the CTI and RRH components of the intervention over time. However, it is highly likely that at least some individuals who would theoretically be targeted for and receive a CTI-based RRH intervention would ultimately require housing and additional supports that are more intensive and of longer duration. Thus, a successful CTI-based RRH intervention would include a formalized mechanism to assess whether participants need additional supports and should be connected with interventions like PSH that may be more appropriately calibrated to their longer-term. Such an approach is, in concept, entirely consistent with the goals of the "try-out" and "transition of care" phases of the CTI. This approach is also consistent with a "progressive engagement" model of providing housing 
supports (Culhane et al., 2011), wherein individuals are initially given less intensive supports, and then their needs are periodically re-assessed with supports increased those determined to require more assistance. This progressive engagement approach would have the added benefit of making more efficient use of relatively more expensive interventions like $\mathrm{PSH}$, because, in theory, only those for whom the less expensive CTI-based RRH model was insufficient for maintaining housing stability would progress to a more expensive form of intervention.

\section{Medicaid Challenges}

In the American context, using Medicaid funds to scale-up a CTI-based RRH model would require states to determine how to redesign their Medicaid benefits to make CTI a covered service. In some states, CTI is already a covered service under the rehabilitation option of Medicaid. Other states might pursue other options for making CTI a covered service. One particularly promising avenue would be to incorporate a CTIbased RRH program as part of the services provided by Medicaid Accountable Care Organizations (ACOs). ACOs are provider-led organizations that typically include a network of participating providers who receive a capitated per-patient payment to assume the full financial risk of meeting all of their members' care needs. ACOs share in any savings that materialize from their members making less costly use of care than expected (Center for Health Care Strategies, 2018). More than a dozen states have implemented or are in the process of implementing Medicaid ACOs. Integrating CTIRRH into ACO service packages would be consistent with their objectives and align with their incentives. Ultimately, federal guidance on these issues could prove useful to states in amending their state Medicaid plans to include CTI, and would also help to ensure consistency of the program model across the country.

\section{Temporary Financial Assistance}

Temporary financial assistance (TFA) for housing-related needs is an essential component of the RRH, but not the CTI program model. Recent work shows RRH recipients who receive
TFA are more likely to exit stable housing than those who do not (Nelson et al., 2021). However, the U.S. federal government has been explicit that Medicaid dollars cannot be used to directly pay for housing costs (Center for Medicare \& Medicaid Services, 2015), and, in the United States, it would therefore be a challenge to find resources to pay for the TFA component of RRH. Recent evidence from the VA's SSVF program finds that households receiving TFA through that program's RRH component receive an average amount of $\$ 6,000$ in TFA (Nelson et al., 2021). Applying this figure to our estimate of 1.17 million individuals who would theoretically be targeted for TFA nets out to a total cost of roughly $\$ 7$ billion. The most obvious source of this funding would be federal homeless assistance dollars from the Department of Housing and Urban Development (HUD), and should our proposal be implemented, any increased HUD funding for RRH could be used exclusively for TFA. Yet, at present, such funds only amount to about $\$ 4$ billion (Culhane \& An, 2021), and thus, additional funds would be needed. To the extent that our proposal resulted in reduced demand for emergency shelter and transitional housing programs (a prospect we view as highly likely), resources currently used to operate these services could be shifted to TFA for RRH, thereby creating a virtuous cycle in addressing homelessness. One recent estimate suggests that non-profit providers of emergency shelter and transitional housing receive $\$ 8.5$ billion in revenue on an annual basis (Culhane \& An, 2021), meaning that repurposing of these resources would be more than sufficient to cover the costs of our proposal.

Locating additional funding sources to provide TFA to more individuals experiencing crisis homelessness should also be included in broader ongoing policy discussions related to homelessness and housing affordability. Such discussions are rising higher on the policy agenda in the United States both in light of a widespread, affordable housing problem that existed prior to Covid-19 and because of the emphasis on housing in economic stimulus packages and other measures enacted in response to the pandemic. Thus, the policy context is highly dynamic, and there is a real possibility of securing substantial new resources for TFA. 


\section{Conclusion}

The United States and other countries of the global North have, by and large, failed to implement adequate strategies for people experiencing crisis homelessness, despite the fact that such individuals account for large shares of the homeless population. The scaling-up of a CTI-based RRH model presents an opportunity to address this longstanding shortcoming of policy responses to homelessness. In the United States, leveraging resources from Medicaid, the public health insurance program for low-income individuals, offers an unprecedented opportunity to use funds from an entitlement source to implement a scalable solution to crisis homelessness. This proposal would allow the homelessness assistance system to be more effective in terms of stabilizing housing crises that lead to homelessness and extricating people from the potential downward spiral and negative impacts of homelessness.

The specific contours of how a CTI-based RRH model could be taken to scale in other countries would obviously vary from what we have proposed above. Nonetheless, we believe the benefits for individuals and society would be realized, regardless of the context. To ensure that such benefits are realized, rigorous impact evaluation and model refinement would thus be critical components of an expansion of integrated CTI/RRH programs across all settings.

The Covid-19 pandemic has demonstrated that swift and radical changes to how societies and governments approach homelessness are possible. These quick pivots to adopting new approaches in response to Covid-19 are not fully sufficient for ending homelessness, but the give reason for optimism that it will be possible to continue to move the needle. Indeed, as many societies have been willing to pay for emergency shelter and meal programs, we now have reason to believe that they would be willing to pay for the emergency housing and relocation assistance that is far more humane and can better avert the damage of homelessness.

\section{References}

Byrne, T., Fargo, J. D., Montgomery, A. E., Munley, E., \& Culhane, D. P. (2014). The relationship between community investment in permanent supportive housing and chronic homelessness. Social Service Review, 88(2). https://doi.org/10.1086/676142

Center for Health Care Strategies. (2018). Medicaid accountable care organizations: State update.

https:// www.chcs.org/media/ACO-FactSheet-02-27-2018-1.pdf

Center for Medicare \& Medicaid Services. (2015). CMCS informational bulletin: Coverage of housing-related activities and services for individuals with disabilities. https:/ / www.medicaid.gov/federal-policyguidance/downloads/CIB-06-26-2015.pdf

Connecticut Coalition to End Homelessness. (2018). Critical time intervention/rapid Rehousing Pilot. http://cceh.org/cti-rrh/

Culhane, D.P., Metraux, S., \& Byrne, T. (2011). A prevention-centered approach to homelessness assistance: A paradigm shift? Housing Policy Debate, 21(2). https://doi.org/10.1080/10511482.2010.536 246

Culhane, D.P., Treglia, D., Steif, K., Kuhn, R., \& Byrne, T. (2020). Estimated emergency and observational/quarantine capacity need for the US homeless population related to COVID-19 exposure by County; Projected hospitalizations, intensive care units and mortality. https://works.bepress.com/dennis_culhane /237/

Culhane, Dennis P., \& An, S. (2021). Estimated revenue of the nonprofit homeless shelter industry in the United States: Implications for a more comprehensive approach to unmet shelter demand. https://doi.org/10.1080/10511482.2021.190 5024

Culhane, Dennis P., Metraux, S., \& Byrne, T. (2011). A prevention-centered approach to homelessness assistance: a paradigm shift? Housing Policy Debate, 21(2), 295-315. https://www.usich.gov/resources/uploads /asset_library/DennisCulhane_PrevCentAp proHomelessnessAssist.pdf

Dej, E., Gaetz, S., \& Schwan, K. (2020). Turning off the tap: A typology for homelessness prevention. Journal of Primary Prevention 41(5) 397-412. https://doi.org/10.1007/s10935020-00607-y

DiPietro, B., Artiga, S., \& Gates, A. (2014). Early impacts of the medicaid expansion for the 
homeless

http:/ / files.kff.org/attachment/early-

impacts-of-the-medicaid-expansion-for-the-

homeless-population-issue-brief

Evans, W. N., Kroeger, S., Palmer, C., \& Pohl, E. (2019). Housing and urban developmentVeterans affairs supportive housing vouchers and Veterans' homelessness, 20072017. American Journal of Public Health, 109(10), 1440-1445. https://doi.org/10.2105/ AJPH.2019.305231

Gubits, D., Shinn, M., Wood, M., Brown, S. R., Dastrup, S. R., \& Bell, S. H. (2018). What interventions work best for families who experience homelessness? Impact estimates from the family options study. Journal of Policy Analysis and Management, 37(4), 835866. https:/ /doi.org/10.1002/pam.22071

Henwood, B. F., Stefancic, A., Petering, R., Schreiber, S., Abrams, C., \& Padgett, D. K. (2015). Social relationships of dually diagnosed homeless adults following enrollment in housing first or traditional treatment services. Journal of the Society for Social Work and Research, 6(3), 385-406. https://doi.org/10.1086/682583

Herman, D., Conover, S., Felix, A., Nakagawa, A., \& Mills, D. (2007). Critical time intervention: An empirically supported model for preventing homelessness in high risk groups. The Journal of Primary Prevention, 28(3-4), 295-312. https://doi.org/10.1007/s10935007-0099-3

Herman, D., Conover, S., Gorroochurn, P., Hinterland, K., Hoepner, L., \& Susser, E. S. (2011). Randomized trial of critical time intervention to prevent homelessness after hospital discharge. Psychiatric Services, 62(7), 713-719.

https://doi.org/10.1176/ps.62.7.pss6207_07 13

Herman, D., Hanesworth, C., \& Catell Noll, B. (2017). Critical time intervention for rapid rehousing: Manual for case managers and supervisors. http://cceh.org/wpcontent/uploads/2017/02/Critical-TimeIntervention-for-Rapid-RehousingManual.pdf

Hwang, S. (2001). Homelessness and health. Canadian Medical Association Journal, 164(2), 229-233. http://www.nlc-bnc.ca/eppparchive/100/201/300/cdn_medical_associat ion/cmaj/vol-164/issue-2/pdf/pg229.pdf

Jones, K., Colson, P. W., Holter, M. C., Lin, S., Valencia, E., Susser, E., \& Wyatt, R. J. (2003). Cost-effectiveness of critical time intervention to reduce homelessness among persons with mental illness. Psychiatric Services, 54(6), 884-890. https://doi.org/10.1176/appi.ps.54.6.884

Latimer, E. A., Rabouin, D., Cao, Z., Ly, A., Powell, G., Aubry, T., Distasio, J., Hwang, S. W., Somers, J. M., Stergiopoulos, V., Veldhuizen, S., Moodie, E. E. M., Lesage, A., Goering, P. N., \& Investigators, for the A. H. S. (2017). Costs of services for homeless people with mental illness in 5 Canadian cities: A large prospective follow-up study. CMAJ Open, 5(3), E576-E585. https://doi.org/10.9778/cmajo.20170018

Ly, A., \& Latimer, E. (2015). Housing first impact on costs and associated cost offsets : A review of the literature. Canadian Journal of Psychiatry, 60(11), 475-487. https://doi.org 10.1177/070674371506001103.

National Alliance to End Homelessness. (2016). Rapid re-housing performance benchmarks and program standards. http:/ / www.endhomelessness.org/page//files/Rapid Re-Housing Performance Benchmarks and Program Standards_2016.pdf

Nelson, R. E., Byrne, T. H., Suo, Y., Cook, J., Pettey, W., Gundlapalli, A. V., Greene, T., Gelberg, L., Kertesz, S. G., Tsai, J., \& Montgomery, A. E. (2021). Association of temporary financial assistance with housing stability among US Veterans in the supportive services for Veteran families program. JAMA Network Open, 4(2), e2037047.

https:/ / doi.org/10.1001/jamanetworkopen. 2020.37047

Parsell, C., Clarke, A., \& Kuskoff, E. (2020). Understanding responses to homelessness during COVID-19: An examination of Australia. Housing Studies, 1-14. https:/ / doi.org/10.1080/02673037.2020.182 9564

Perri, M., Dosani, N., \& Hwang, S. W. (2020). COVID-19 and people experiencing homelessness: challenges and mitigation strategies. CMAJ, 192(26), E716-E719. https://doi.org/10.1503/CMAJ.200834 
Piña, G., \& Pirog, M. (2019). The impact of homeless prevention on residential instability: Evidence from the homelessness prevention and rapid re-housing program. Housing Policy Debate, 29(4), 501-521. https://doi.org/10.1080/10511482.2018.153 2448

Pleace, N., Baptista, I., Benjaminsen, L., \& BuschGeerstema, V. (2018). Homelessness services in Europe: European observatory on homelessness comparative studies on homelessness. https://eprints.whiterose.ac.uk/142819/

Pleace, N., Culhane, D. P., Granfelt, R., \& Knutagard, M. (2015). The finnish homelessness strategy: An international review. https://www.york.ac.uk/media/chp/docu ments/2015/YMra_3en_2015.pdf

Priorities, C. on B. and P. (2020). Policy basics: Introduction to medicaid. https://www.cbpp.org/research/health/in troduction-to-medicaid

Rodriguez, J. M., \& Eidelman, T. A. (2017). Homelessness interventions in Georgia: Rapid re-housing, transitional housing, and the likelihood of returning to shelter. Housing Policy Debate, 27(6), 825-842. https://doi.org/10.1080/10511482.2017.131 3292

Schwarcz, S. K., Hsu, L. C., Vittinghoff, E., Vu, A., Bamberger, J. D., Katz, M. H., Hanzlick, R., Parrish, R., Hibbs, J., Benner, L., Klugman, L., Spencer, R., Macchia, I., Mellinger, A., Fife, D., Hwang, S., Barrow, S., Herman, D., Cordova, P., ... Houghton, T. (2009). Impact of housing on the survival of persons with AIDS. BMC Public Health, 9(1), 220. https://doi.org/10.1186/1471-2458-9-220

Scottish Government. (2020). Ending homelessness together: Updated action plan - October 2020. https://www.gov.scot/publications/endin g-homelessness-together-updated-actionplan-october-2020/pages/4/

Stergiopoulos, V., Mejia-Lancheros, C.,
Nisenbaum, R., Wang, R., Lachaud, J., O'Campo, P., \& Hwang, S. W. (2019). Longterm effects of rent supplements and mental health support services on housing and health outcomes of homeless adults with mental illness: extension study of the At Home/Chez Soi randomised controlled trial. The Lancet. Psychiatry, $0(0)$. https://doi.org/10.1016/S22150366(19)30371-2

Susser, E., Valencia, E., Conover, S., Felix, A., Tsai, W. Y., \& Wyatt, R. J. (1997). Preventing recurrent homelessness among mentally ill men: a "critical time" intervention after discharge from a shelter. American Journal of Public Health, 87(2), 256-262. https://doi.org/10.2105/AJPH.87.2.256

U.S. Department of Housing and Urban Development. (2017). The 2017 annual homeless assessment report to congress, Part 1: Point-in-Time Estimates of Homelessness. https:// socialinnovation.usc.edu/homeless _research/the-2017-annual-homelessassessment-report-ahar-to-congress-part-1point-in-time-estimates-of-homelessness /

U.S. Department of Housing and Urban Development. (2020a). The 2018 annnual homeless assessment report to congress, Part 2: Estimates of homelessness in the United States. https://www.huduser.gov/portal/sites/de fault/files/pdf/2018-AHAR-Part-2.pdf

U.S. Department of Housing and Urban Development. (2020b). The 2019 annual homeless assessment report to congress: Part 1PIT estimates of homelessness in the U.S. https://www.huduser.gov/portal/sites/default/file s/pdf/2019-AHAR-Part-1.pdf

Y Foundation. (2018). A home of your own: Housing first and ending homelessness in Finland. Y Foundation. https://ysaatio.fi/assets/files/2018/01/A_ Home_of_Your_Own_lowres_spreads.pdf 